\title{
Time-dependent effects of Prkce deletion on glucose homeostasis and hepatic lipid metabolism on dietary lipid oversupply in mice
}

\author{
K. Raddatz $\cdot$ N. Turner $\cdot$ G. Frangioudakis $\cdot$ B. M. Liao $\cdot$ D. J. Pedersen $\cdot$ J. Cantley $\cdot$ \\ D. Wilks • E. Preston • B. D. Hegarty • M. Leitges • M. J. Raftery • T. J. Biden • \\ C. Schmitz-Peiffer
}

Received: 29 August 2010 /Accepted: 10 January 2011 /Published online: 24 February 2011

(C) Springer-Verlag 2011

\begin{abstract}
Aims/hypothesis We examined the time-dependent effects of deletion of the gene encoding protein kinase $\mathrm{C}$ epsilon (Prkce) on glucose homeostasis, insulin secretion and hepatic lipid metabolism in fat-fed mice.

Methods Prkce ${ }^{--}$and wild-type (WT) mice were fed a high-fat diet for 1 to 16 weeks and subjected to i.p. glucose tolerance tests (ipGTT) and indirect calorimetry. We also investigated gene expression and protein levels by RT-PCR, quantitative protein profiling (isobaric tag for relative and absolute quantification; iTRAQ) and immunoblotting. Lipid levels, mitochondrial oxidative capacity and lipid metabolism were assessed in liver and primary hepatocytes.
\end{abstract}

Electronic supplementary material The online version of this article (doi:10.1007/s00125-011-2073-0) contains supplementary material, which is available to authorised users.

K. Raddatz $(\bowtie) \cdot$ N. Turner $\cdot$ G. Frangioudakis $\cdot$ B. M. Liao ·

D. J. Pedersen $\cdot$ J. Cantley $\cdot$ D. Wilks $\cdot$ E. Preston $\cdot$

B. D. Hegarty $\cdot$ T. J. Biden $\cdot$ C. Schmitz-Peiffer

Garvan Institute of Medical Research,

384 Victoria Street,

Sydney, NSW 2010, Australia

e-mail: k.raddatz@garvan.org.au

N. Turner $\cdot$ T. J. Biden $\cdot$ C. Schmitz-Peiffer

St Vincent's Clinical School, Faculty of Medicine,

University of New South Wales,

Sydney, NSW, Australia

\section{Leitges}

Biotechnology Centre of Oslo, University of Oslo,

Oslo, Norway

M. J. Raftery

Bioanalytical Mass Spectrometry Facility, University of NSW,

Sydney, NSW, Australia
Results While fat-fed WT mice became glucose intolerant after 1 week, Prkce ${ }^{-/-}$mice exhibited normal glucose and insulin levels. iTRAQ suggested differences in lipid metabolism and oxidative phosphorylation between fat-fed WT and Prkce ${ }^{-l-}$ animals. Liver triacylglycerols were increased in fat-fed Prkce $e^{-/-}$mice, resulting from altered lipid partitioning which promoted esterification of fatty acids in hepatocytes. In WT mice, fat feeding elevated oxygen consumption in vivo and in isolated liver mitochondria, but these increases were not seen in Prkce mice. Prkce $e^{-/-}$hepatocytes also exhibited reduced production of reactive oxygen species (ROS) in the presence of palmitate. After 16 weeks of fat feeding, however, the improved glucose tolerance in fat-fed $\mathrm{Prkce}^{-/}$mice was instead associated with increased insulin secretion during ipGTT, as we have previously reported.

Conclusions/interpretation Prkce deletion ameliorates dietinduced glucose intolerance via two temporally distinct phenotypes. Protection against insulin resistance is associated with changes in hepatic lipid partitioning, which may reduce the acute inhibitory effects of fatty acid catabolism, such as ROS generation. In the longer term, enhancement of glucose-stimulated insulin secretion prevails.

Keywords Diabetes - Insulin resistance - Lipid metabolism . Liver $\cdot \mathrm{PKC} \varepsilon \cdot$ Prkce $\cdot$ Protein kinase $\mathrm{C}$ epsilon
Abbreviations
ipGTT Intraperitoneal glucose tolerance test
IRS Insulin receptor substrate
iTRAQ Isobaric tag for relative and absolute quantitation
PKC Protein kinase C
ROS Reactive oxygen species
WT Wild-type 


\section{Introduction}

Type 2 diabetes results from the failure of the pancreatic beta cells to compensate for defective insulin action in peripheral tissues. Obesity is a major contributor to the development of both insulin resistance and beta cell dysfunction, although the underlying mechanisms are not fully understood. The protein kinase C (PKC) family of signalling enzymes has been associated with the generation of lipid-induced insulin resistance in peripheral tissues in many studies involving cultured cells, animal models and humans, and $\mathrm{PKC} \varepsilon$ has been one of the isoforms most often implicated [1]. PKC $\varepsilon$ was shown to be chronically activated in skeletal muscle from fat-fed rats, and changes in its cellular distribution correlated with muscle lipid content [2]. PKCE translocation was also observed in muscles of glucose-infused rats [3], obese Zucker rats [4] and the diabetes-prone sand rat, Psammomys obesus [5]. PKCE activation has also been reported in the liver of fat-fed rats [6], while increased $\mathrm{PKC} \varepsilon$ levels have been found in liver biopsies from obese people with type 2 diabetes [7]. Mechanisms proposed to account for the inhibitory effects of $\mathrm{PKC \varepsilon}$ include serine/threonine phosphorylation of the insulin receptor or insulin receptor substrate 1 (IRS1) to inhibit insulin signal transduction [1].

While these studies were correlative, a causative role for $\mathrm{PKC} \varepsilon$ has been investigated more recently. Knockdown of Prkce prevented hepatic insulin resistance caused by a 3-day high-fat diet, and it was further demonstrated that $\mathrm{PKC} \varepsilon$ could bind to the insulin receptor, inhibiting its tyrosine kinase activity [8]. In contrast, we recently showed that deletion of Prkce in mice fed a longer-term high-fat diet compensates for insulin resistance by augmenting insulin levels, due in part to increased insulin secretion by the pancreas and in part to diminished insulin clearance by the liver [9]. We therefore hypothesised that, in the context of lipid-induced insulin resistance, $\mathrm{PKC} \varepsilon$ plays only an initial transient role. Here we show that the effects of Prkce deletion on glucose homeostasis are indeed dependent on the duration of dietary treatment. Unexpectedly, we also demonstrate that the absence of $\mathrm{PKC} \varepsilon$ transiently promotes acute hepatic lipid accumulation in fat-fed mice.

\section{Methods}

Mice The generation and maintenance of wild-type (WT) and Prkce knockout mice was described previously [9]. Ethical approval for mouse studies was granted by the Garvan/St Vincent's Hospital Animal Ethics Committee. Mice at 68 weeks of age were fed either a standard chow diet $(10.88 \mathrm{~kJ} / \mathrm{g} ; 8 \%$ fat, $21 \%$ protein and $71 \%$ carbohydrate; Gordon's Specialty Stock Feeds, Yanderra, NSW, Australia) or with a lard-based high-fat diet prepared in-house $(19.67 \mathrm{~kJ} / \mathrm{g}, 45 \%$ fat, $20 \%$ protein and $35 \%$ carbohydrate, based on rodent diet D12451; Research Diets, New Brunswick, NJ, USA) for up to 16 weeks. Mice were fasted for $6 \mathrm{~h}$ prior to i.p. glucose tolerance tests (ipGTTs), and blood glucose and insulin levels were determined as described previously [9]. An insulin resistance index was calculated from the product of glucose and insulin levels [10].

Islet isolation and insulin secretion assays Islets were isolated as previously described [11]. After pancreatic digestion, islets were purified using a Ficoll-Paque (GE Healthcare, Chalfont St Giles, UK) gradient. For insulin secretion assays, islets were preincubated for $1 \mathrm{~h}$ in KrebsRinger buffer containing HEPES (KRBH), 0.1\% (wt/vol.) BSA and $2 \mathrm{mmol} / 1$ glucose. Batches of five islets were incubated at $37^{\circ} \mathrm{C}$ for $1 \mathrm{~h}$ in $130 \mu \mathrm{KRBH}$ containing $0.1 \%$ (wt/vol.) BSA and $2 \mathrm{mmol} / \mathrm{l}$ glucose (basal), supplemented with glucose (final concentration $6.5,11$ or $20 \mathrm{mmol} / \mathrm{l}$ ) or $25 \mathrm{mmol} / \mathrm{l} \mathrm{KCl}$, as indicated.

Oil Red O staining Livers from WT and Prkce ${ }^{-/-}$mice fed either chow or a high-fat diet for 1 week were fixed in $4 \%$ (wt/vol.) paraformaldehyde in PBS for $4 \mathrm{~h}$, followed by overnight incubation in $30 \%$ (wt/vol.) sucrose. The tissue was embedded in OCT Tissue-Tek medium (Sakura Finetech USA, Torrance, CA, USA) and cut into $5 \mu \mathrm{m}$ sections (CM3050 S; Leica). Staining was performed as described by Preece [12]. Image analysis was carried out with a DMRB2500 microscope (Leica).

Tissue and plasma lipid content Lipid extracts were obtained from $25 \mathrm{mg}$ of liver or quadriceps muscle according to Folch et al. [13] and used for analysis of individual lipids. Triacylglycerol was measured with a colorimetric assay (Roche Diagnostics, Indianapolis, IN, USA). Cholesterol and cholesteryl ester were determined with a cholesterol assay kit (Calbiochem, San Diego, CA, USA). Diacylglycerol content was assessed by thin-layer chromatography (TLC), using a method adapted from Nakamura and Handa $[14,15]$. NEFA were determined in plasma samples from 1 week chow or fat-fed WT and Prkce $^{-/-}$mice using the NEFA C kit from Wako Diagnostics (Richmond, VA, USA).

Indirect calorimetry Oxygen consumption $\left(\mathrm{VO}_{2}\right)$, carbon dioxide production $\left(\dot{V} \mathrm{CO}_{2}\right)$ and respiratory exchange ratio were determined simultaneously by indirect calorimetry (Oxymax, Columbus Instruments, Columbus, OH, USA) as described previously [16]. All values were normalised for lean body mass, determined by dual-energy X-ray absorptiometry (Lunar PIXImus2 mouse densitometer; GE Healthcare). 
Mitochondrial respiration Mitochondria were isolated from liver as described by Bruce et al. [17]. Oxygen consumption was measured at $30^{\circ} \mathrm{C}$ with a Clark-type oxygen electrode (Strathkelvin Instruments, Motherwell, UK). For each assay, 0.5-0.8 $\mathrm{mg}$ mitochondria were used in the presence of either $5 \mathrm{mmol} / \mathrm{l}$ glutamate and $2.5 \mathrm{mmol} /$ 1 malate or $10 \mathrm{mmol} / 1$ succinate and $4 \mu \mathrm{mol} / 1$ rotenone as substrates, and state III respiration was initiated by the addition of $0.2 \mathrm{mmol} / \mathrm{l}$ ADP [16].

$\left[{ }^{14}\right.$ C]Palmitate labelling of hepatocytes Hepatocytes from WT and Prkce ${ }^{-/-}$mice fat-fed for 1 week were isolated as described previously $[18,19]$ and seeded on 12-well plates at a cell density of $3.2 \times 10^{5}$ cells $/ \mathrm{ml}$. Sixteen hours after attachment, cells were treated with $0.4 \mathrm{mmol} / \mathrm{l}$ palmitate coupled to $0.9 \%$ (wt/vol.) BSA and $0.74 \mathrm{MBq} / \mathrm{ml}\left[\mathrm{U}-{ }^{14} \mathrm{C}\right]$ palmitate $(1.76 \mathrm{TBq} / \mathrm{mol})$ for $24 \mathrm{~h}$. To measure $\left[{ }^{14} \mathrm{C}\right]$ palmitate incorporation, lipids were extracted from the cells and analysed by TLC as described previously [9, 20]. For secretion studies, cells were further incubated in palmitatefree medium for $24 \mathrm{~h}$. Lipids were extracted from the cell culture medium and analysed by TLC.

Determination of reactive oxygen species Mitochondrial reactive oxygen species (ROS) were measured in hepatocytes from 1 week fat-fed WT and Prkce ${ }^{-/-}$mice after $16 \mathrm{~h}$ of treatment with $0.4 \mathrm{mmol} / 1$ palmitate coupled to $0.9 \%$ (wt/vol.) BSA using Mitosox Red and 5-(and-6)-chloromethyl-2',7'-dichlorodihydrofluorescein diacetate, acetyl ester $\left(\mathrm{CM}-\mathrm{H}_{2} \mathrm{DCFDA}\right)$ according to the manufacturer's instructions (Invitrogen, Carlsbad, CA, USA).

Statistics Student's $t$ test and one-way and factorial ANOVA were performed using GraphPad Prism 5 (GraphPad Software, La Jolla, CA, USA) or STATA/SE9.2 (STATA, College Station, TX, USA) software. Differences were considered significant at $p<0.05$.

\section{Results}

Time-dependency of the effects of Prkce deletion To examine the early effects of Prkce deletion on glucose intolerance, we subjected Prkce $e^{-/}$mice and WT littermates to a high-fat diet for 1 week. Fat-fed WT mice showed an impairment in glucose tolerance compared with chow-fed controls, whereas fat-fed Prkce $e^{-/-}$mice exhibited normal glucose tolerance (Fig. 1a). Fat-fed Prkce $e^{-/-}$mice also had lower insulin levels than fat-fed WT mice during the ipGTT (Fig. 1b), and thus a lower insulin resistance index (Fig. 1c). This contrasts with our previous studies employing a high-fat diet for 16 weeks, in which we showed improved glucose tolerance associated with elevated insulin levels in fat-fed Prkce $e^{-/-}$mice [9]. To investigate this discordance further, we examined glucose tolerance at several intervals in WT and Prkce ${ }^{-1-}$ mice fed a high-fat diet for up to 16 weeks. Prkce ${ }^{-/-}$mice maintained improved glucose tolerance over the entire study (Fig. 2a-c), and still exhibited glucose tolerance similar to that of chow-fed WT mice at 16 weeks (see Electronic supplementary material [ESM] Fig. 1a). However, plasma insulin levels during the ipGTT became significantly elevated in Prkce ${ }^{-/-}$mice compared with WT controls by 6 weeks of fat feeding (Fig. 2d-f), suggesting a loss in the maintenance of insulin sensitivity. This was supported by the change in insulin resistance index over 16 weeks of diet feeding (Fig. 3a), which indicated that Prkce $e^{-/-}$mice were no longer protected against insulin resistance at 16 weeks. However, because glucose tolerance was preserved, our data also suggested the delayed appearance of a favourable beta cell phenotype, which was confirmed by studies in freshly isolated pancreatic islets. Glucose- or KCl-stimulated insulin secretion was not increased in islets from Prkce $^{-1-}$ mice compared with those from WT mice after 1 week of fat feeding, but was elevated after 16 weeks of the diet (Fig. 3b, c). Prkce ${ }^{-/-}$mice therefore appear to be protected from the development of whole-body insulin resistance at an early stage of dietary lipid oversupply, while improved beta cell function compensates for the development of insulin resistance in the longer term, as we have previously reported [9]. In agreement, treatment of WT mice with a $\mathrm{PKC} \varepsilon$ translocation inhibitor peptide in the first week of fat feeding reduced the insulin profile during the ipGTT (ESM Fig. 1b, c), whereas treatment at 10 weeks, while subtly improving glucose tolerance, did so while promoting the insulin response (ESM Fig. 1d, e). Although the effects of the inhibitor were less striking than those of Prkce deletion, they were qualitatively similar in terms of the progression of the phenotypes.

Insulin action in muscle and liver of Prkce ${ }^{-/}$mice fed a high-fat diet for 1 week To determine whether deletion of Prkce promotes insulin action in peripheral tissues after 1 week of fat feeding, we measured glucose uptake after a bolus of insulin using 2-deoxy $\left[{ }^{3} \mathrm{H}\right]$ glucose. While we were able to observe a defect in the insulin-stimulated uptake of glucose into quadriceps muscle in preliminary experiments using mice fed a high-fat diet for 3 weeks (ESM Fig. 2a), no alterations in glucose uptake into muscle or white adipose tissue were observed in fat-fed Prkce ${ }^{-/-}$mice compared with WT mice at 1 week (ESM Fig. 2b, c), suggesting a site of action for $\mathrm{PKC} \varepsilon$ in liver rather than muscle or fat. This was supported by the improved pyruvate tolerance observed in both chow- and fat-fed Prkce ${ }^{-/-}$mice compared with WT control mice (ESM Fig. 2d, e), consistent with an improvement in the suppression of 

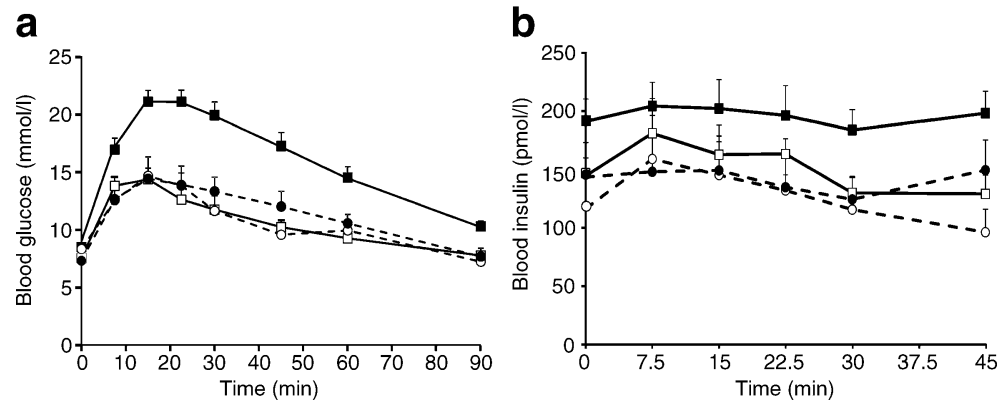

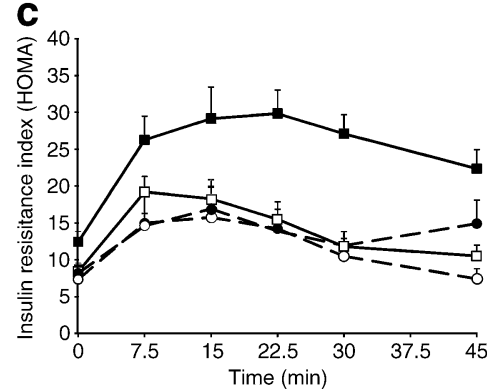

Fig. 1 Deletion of Prkce improves glucose tolerance and insulin homeostasis after 1 week of high-fat feeding. a Blood glucose levels during ipGTT ( $2 \mathrm{~g} / \mathrm{kg}$ ) of WT (chow, $n=12$, white squares; fat, $n=15$, black squares) and Prkce $e^{-/-}$mice (chow, $n=4$, white circles; fat, $n=10$, black circles) fed a high-fat or standard chow diet as controls. b

hepatic gluconeogenesis in these animals. We also measured the insulin-stimulated phosphorylation of the insulin receptor, IRS1, the serine/threonine protein kinase Akt and extracellular signal-regulated kinase (ERK) in vivo, to examine whether the initial improvement in glucose tolerance was related to changes in insulin signalling. In contrast to our findings in liver of mice fat-fed for 16 weeks [9], no diet-induced defect was detected in the phosphorylation of insulin signalling components in either liver or skeletal muscle after 1 week; in addition, Prkce deletion did not enhance insulin signalling under any conditions (ESM Fig. 3).

Altered hepatic lipid metabolism in Prkce ${ }^{-/}$mice To investigate the improvement of glucose homeostasis after
Insulin levels during ipGTT. c Insulin resistance index during ipGTT. For glucose, insulin and insulin resistance index, $p<0.001$ for the effect of fat diet in WT mice; $p<0.001$ for the effect of genotype in fat-fed mice (ANOVA)

1 week of fat feeding further, we used iTRAQ as a quantitative proteomic approach to determine $\mathrm{PKC} \varepsilon$ dependent changes in protein levels. Liver lysates from chow- and fat-fed WT and Prkce ${ }^{-/-}$mice were labelled with different isobaric tags and subjected to HPLC/MS-MS. We detected 39 proteins with altered levels in fat-fed Prkce ${ }^{-/-}$ mice (ESM Table 1). These included several proteins involved in lipid metabolism, such as carboxylesterase ML1 and acyl carrier protein, suggestive of differences in fatty acid handling between WT and Prkce ${ }^{-/-}$mice. We therefore examined the accumulation of lipids in liver and muscle. Liver sections stained with Oil Red $\mathrm{O}$ indicated increased hepatic lipid accumulation in fat-fed Prkce mice (Fig. 4a). This was confirmed by measuring the content of different lipid species. Fat feeding caused a
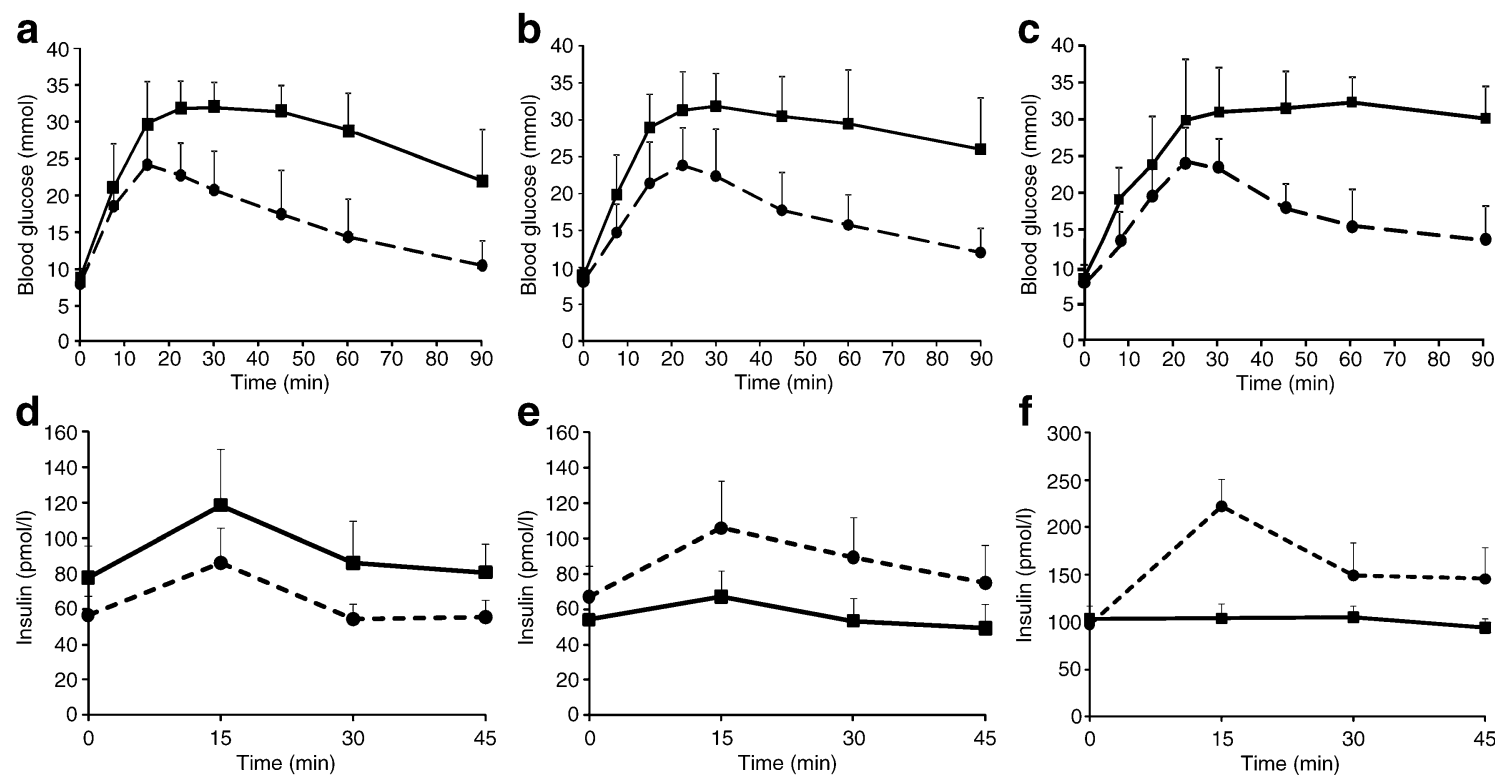

Fig. 2 Effects of Prkce deletion on glucose and insulin levels during long-term lipid oversupply. WT ( $n=9$, squares) and Prkce ${ }^{-/-}$mice $(n=$ 6 , circles) were fat-fed for 16 weeks and ipGTTs $(3 \mathrm{~g} / \mathrm{kg})$ were performed at $3(\mathbf{a}, \mathbf{d}), 6(\mathbf{b}, \mathbf{e})$ and $16(\mathbf{c}, \mathbf{f})$ weeks. Blood glucose $(\mathbf{a}-\mathbf{c})$ and insulin levels $(\mathbf{d}-\mathbf{f})$ are shown. $p<0.001$ for effect of genotype on glucose and insulin levels at each time point (ANOVA) 

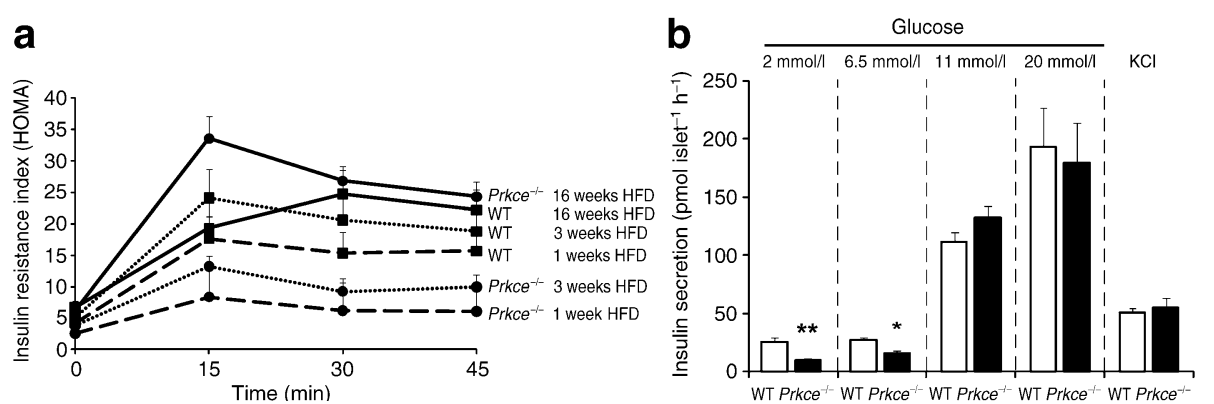

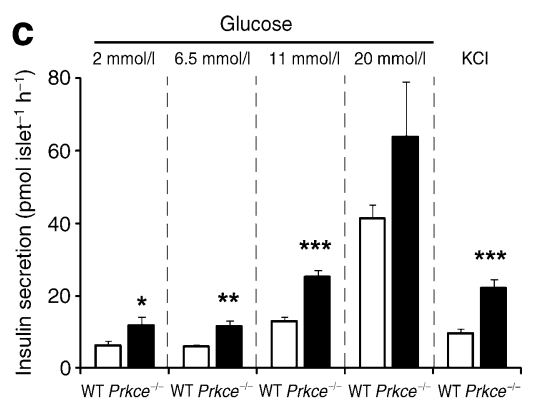

Fig. 3 Effect of fat diet on insulin resistance index and insulin secretion in WT and Prkce ${ }^{-/-}$mice over time. a The insulin resistance index was calculated for Prkce $e^{-/-}$and WT mice fat-fed (HFD) for 1, 3 and 16 weeks. $p<0.05$ for effect of diet duration (ANOVA). Glucose- and $\mathrm{KCl}$-stimulated insulin secretion was measured in freshly isolated pancreatic islets from WT and Prkce ${ }^{-/-}$mice $(n=2)$ after (b) 1 week or (c) 16 weeks of fat feeding. ${ }^{*} p<0.05, * * p<0.01, * * * p<0.001$, Prkce ${ }^{-/-}$ vs WT islets (Student's $t$ test) markedly larger increase in hepatic triacylglycerol levels in Prkce ${ }^{-/-}$mice compared with WT mice at 1 week (approximately fourfold vs 1.3-fold; Fig. 4b), which was accompanied by elevated levels of diacylglycerols (Fig. 4c) and cholesterol (Fig. 4d). NEFA levels were not different between the genotypes (Fig. 4e), but significantly elevated by fat feeding in plasma. Importantly, hepatic triacylglycerol levels were further elevated after 16 weeks of fat feeding, by which time there was no difference between WT and Prkce ${ }^{-l-}$ mice (Fig. 4f). In contrast, the accumu-
Fig. 4 Accumulation of neutral lipids in the liver of Prkce mice fat-fed for 1 week. a Oil Red $\mathrm{O}$ staining of liver sections from WT and Prkce ${ }^{-/-}$mice fed a high-fat diet or chow as control. Results are typical of sections from four mice per group. Scale bar, $50 \mu \mathrm{m}$. Levels of triacylglycerol (b), diacylglycerol (c), cholesterol (d, lower bars) and cholesteryl ester (CE) (d, hatched bars) were measured in extracts from livers of chow (white bars, $n=6$ per group) and fat-fed (black bars, $n=8$ per group) mice after 1 week. e Levels of NEFA in the plasma of WT $(n=10)$ and Prkce $(n=5)$ mice fed chow or fat-fed for 1 week. Triacylglycerol was measured in liver after 16 weeks (f) and in quadriceps muscle after 1 week (g) and 16 weeks (h) of chow or fat feeding. ${ }^{\|} p<0.05,{ }^{\dagger} p<0.005$ for effect of diet in Prkce ${ }^{-/-}$vs WT mice after 1 week (ANOVA); ${ }^{\star} p<0.05$, ${ }^{\dagger \dagger} p<0.06$ for effect of genotype in fat-fed mice (ANOVA); $\S_{p}<0.05$ for effect of diet on cholesterol in Prkce $e^{-/-}$vs WT mice (ANOVA); ${ }^{\natural} p<0.05$ for effect of diet on cholesteryl ester in Prkce $^{-/-}$vs WT mice (ANOVA). ${ }^{*} p<0.05,{ }^{* *} p<0.01$, $* * * p<0.005$ (Student's $t$ test)
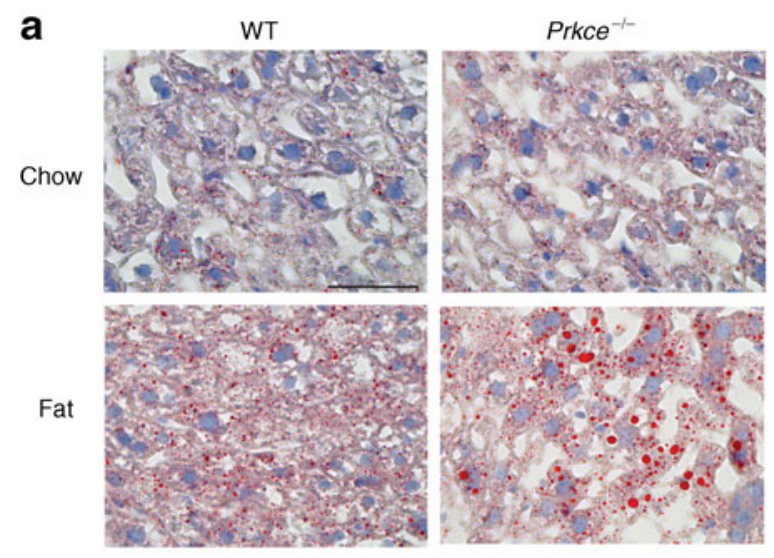

b
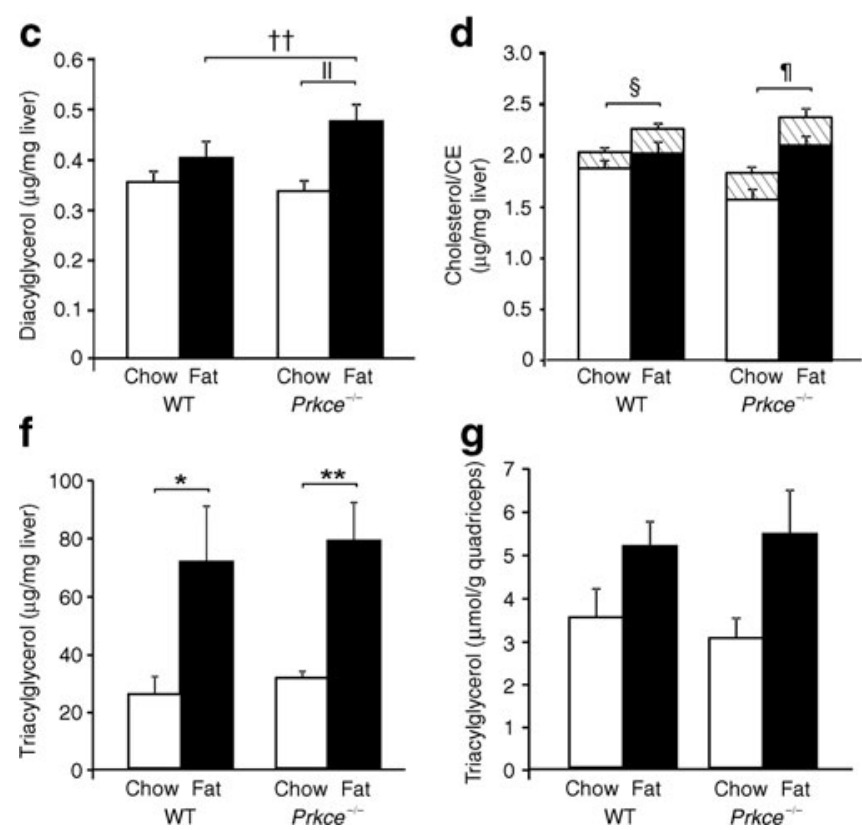
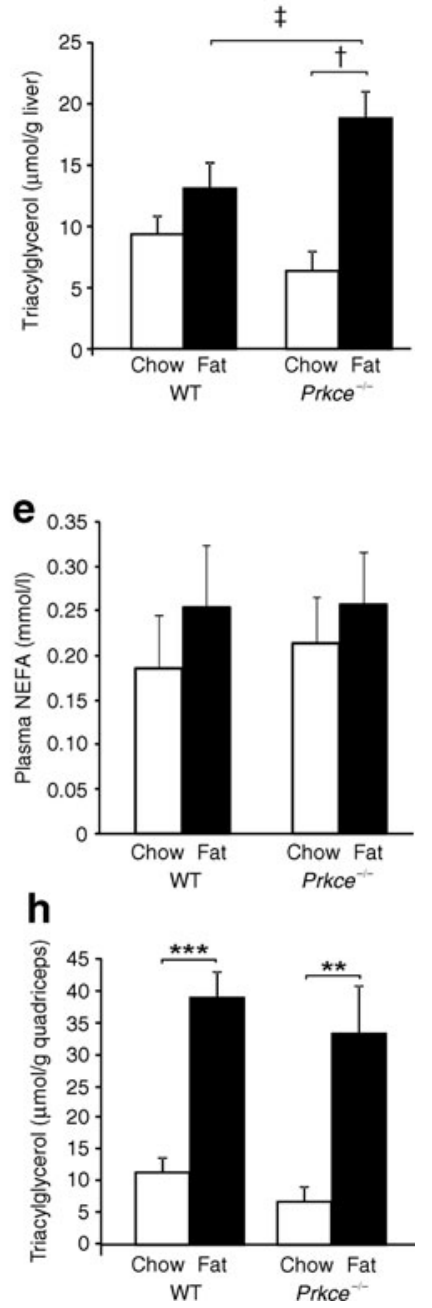
lation of triacylglycerol in skeletal muscle induced by fat feeding was unaffected by Prkce deletion at either time point (Fig. 4g, h).

Effects of Prkce deletion on energy expenditure and mitochondrial activity in fat-fed mice To determine why acute hepatic lipid accumulation was exacerbated in Prkce ${ }^{-/-}$ mice, we first carried out in vivo metabolic assessments. No significant differences in food intake or body weight were observed between WT and Prkce ${ }^{-/-}$mice after 1 week of fat diet feeding (ESM Fig. 4a, b). Indirect calorimetry indicated that fat-fed WT and Prkce ${ }^{-/-}$mice each had a lower respiratory exchange ratio than chow-fed animals, especially during the dark phase (Fig. 5a, ESM Fig. 4c), indicating a similarly increased use of fat rather than carbohydrate as oxidative fuel. However, while $\dot{V} \mathrm{O}_{2}$ was higher in fat-fed WT mice when compared with chow-fed controls, indicating increased energy expenditure, this increase was significantly diminished in fat-fed Prkce $^{-/-}$ mice (Fig. 5b, ESM Fig. 4d). In agreement, we also observed elevated oxygen consumption in mitochondria isolated from livers of fat-fed WT mice when compared with livers from chow-fed control mice (Fig. 5c), whereas mitochondria from fat-fed Prkce $e^{-/-}$mice did not exhibit this increase. However, significant genotype-dependent differences in the activity of the individual mitochondrial complexes I-IV (ESM Fig. 5a-d), ATP synthase (ESM Fig. 5e) or citrate synthase (ESM Fig. 5f) were not observed. There was also no corresponding difference in the abundances of several marker proteins of the mitochondrial complexes, in the activity of $\beta$-hydroxyacyl-CoA dehydrogenase and medium-chain acyl-CoA dehydrogenase, or in ketone body synthesis (ESM Fig. 5g-j). Therefore, while Prkce deletion modulated in vivo respiration and the activity of intact mitochondria, this may not be explained by direct effects on the expression of the markers of respiration or $\beta$-oxidation we have measured.

Enhanced fatty acid esterification in Prkce $e^{--}$hepatocytes We investigated whether the accumulation of hepatic lipid in Prkce $^{---}$mice was also associated with increased fatty acid esterification. Hepatocytes isolated from WT and Prkce $^{-/-}$mice fat-fed for 1 week were cultured with $\left[{ }^{14} \mathrm{C}\right]$ palmitate for $24 \mathrm{~h}$. Incorporation of $\left[{ }^{14} \mathrm{C}\right]$ palmitate into neutral lipids (triacylglycerol, diacylglycerol and cholesteryl ester) was indeed greatly enhanced in Prkce ${ }^{-/}$ hepatocytes (Fig. 6a). The accumulation of lipid esters was not explained by diminished secretion of lipid by Prkce $^{-/}$hepatocytes, as this was also elevated (Fig. 6b). Furthermore, this accumulation was most likely due to posttranslational effects of $\mathrm{PKC} \varepsilon$, because the mRNA levels of acyl transferases and lipases, as well as key transcription
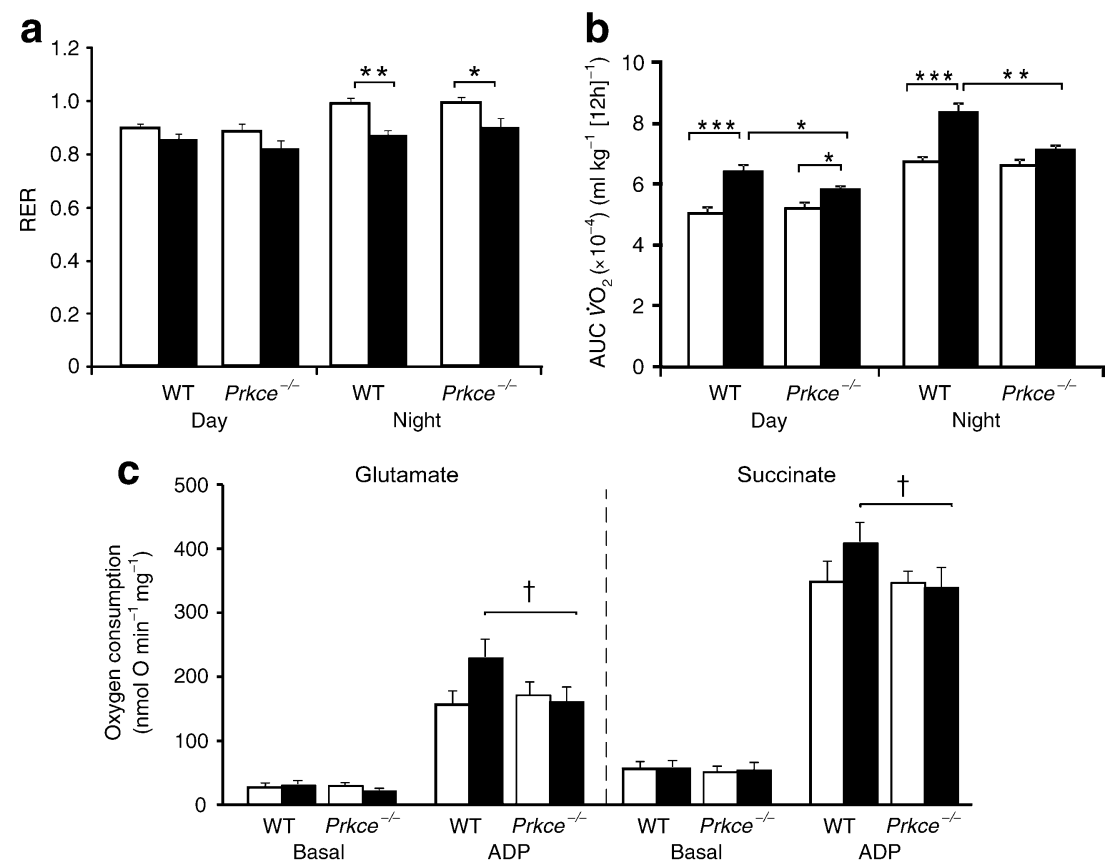

Fig. 5 Reduced mitochondrial oxygen consumption in fat-fed Prkce mice. Indirect calorimetry of WT $(n=5)$ and Prkce $e^{-/-}$mice $(n=5)$ fed a chow (white bars) or fat diet (black bars) for 1 week. Respiratory exchange ratio (RER) (a) and oxygen consumption (b) for the light $(12 \mathrm{~h})$ and dark $(12 \mathrm{~h})$ period. $* p<0.05, * * p<0.01, * * * p<0.005$
(Student's $t$ test). c Basal and ADP-stimulated respiration in freshly isolated liver mitochondria from chow-fed (black bars) and fat-fed (white bars) WT and Prkce ${ }^{-/-}$mice ( $n=8-10$ per group) using glutamate or succinate as substrates. ${ }^{\dagger} p<0.05$ for combined effect of genotype and diet in the presence of ADP (ANOVA) 
factors regulating lipid metabolism (ESM Fig. 6a-c) were unchanged in Prkce $e^{-/-}$liver. Similarly, the protein levels of sterol regulatory element binding protein 1c (SREBP1c) and fatty acid synthase was not different between liver of fat-fed WT and Prkce ${ }^{-/-}$mice (ESM Fig. 6d, e).

Reduced generation of ROS may link the altered lipid metabolism with prevention of insulin resistance in Prkce--mice Taken together, our data indicate that a major effect of Prkce deletion upon short-term dietary lipid oversupply is to redirect hepatic fatty acid metabolism away from $\beta$-oxidation towards esterification, which correlates with the transient protection from insulin resistance. To determine whether lipid repartitioning may reduce harmful effects of lipid oxidation, we first examined if signalling enzymes, already well established in the generation of insulin resistance, were affected. We did not observe alterations in the phosphorylation of the inflammatory mediators c-Jun N-terminal kinase $(\mathrm{JNK})$ and IKB kinase beta (IKK $\beta)$ in fat-fed Prkce ${ }^{-/-}$mice (ESM Fig. 7a, b). The cytosolic and membrane-associated levels of $\mathrm{PKC}$ isoforms were also unchanged, arguing against a difference in their activation (ESM Fig. 7c-g). Finally, we measured the production of ROS in primary hepatocytes, because these have been linked to insulin resistance [21] and are generated by mitochondria during $\beta$-oxidation and
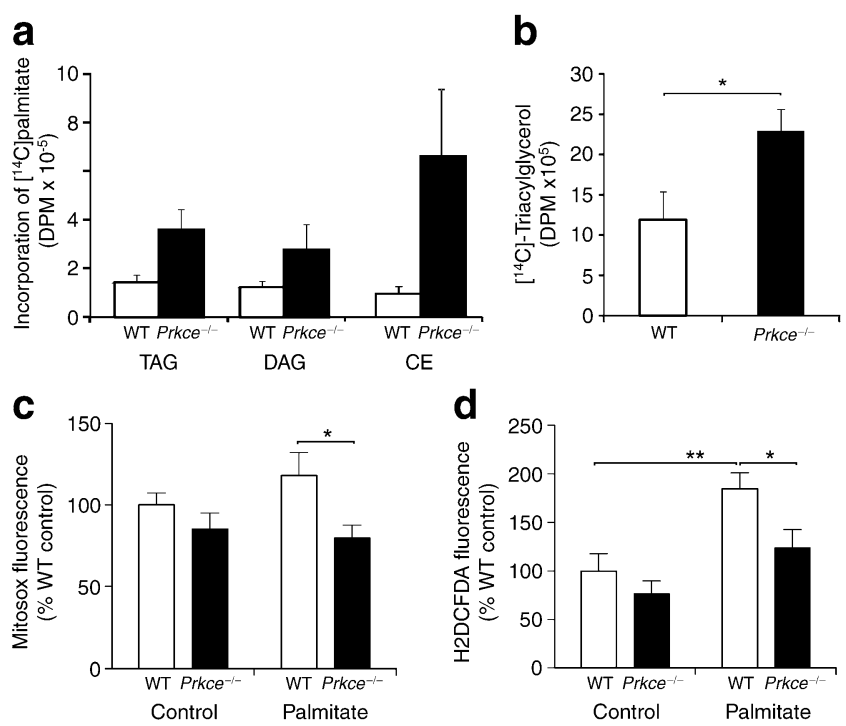

Fig. 6 Hepatocytes from Prkce ${ }^{-/-}$mice show increased fatty acid esterification and reduced mitochondrial ROS production a Incorporation of $\left[{ }^{14} \mathrm{C}\right]$ palmitate into triacylglycerol (TAG), diacylglycerol (DAG) and cholesteryl ester (CE) by hepatocytes isolated from 1 week fat-fed WT $(n=4)$ (white bars) and Prkce $e^{--}$mice $(n=4)$ (black bars) after $24 \mathrm{~h}$ of palmitate treatment $(* p<0.001$ for effect of genotype [ANOVA]) and (b) secretion of ${ }^{14} \mathrm{C}$-labelled triacylglycerol into the medium after incubation of hepatocytes for $24 \mathrm{~h}$ with palmitate and then $24 \mathrm{~h}$ in the absence of palmitate. c, d ROS determination in hepatocytes from fat-fed WT and Prkce ${ }^{-/-}$mice $(n=4)$ using Mitosox Red (c) and CM- $\mathrm{H}_{2}$ DCFDA (d). ${ }^{*} p<0.05,{ }^{*} p<0.01$ (Student's $t$ test) oxidative phosphorylation [22]. The production of ROS was reduced in Prkce $e^{-/-}$hepatocytes incubated in the presence of palmitate (Fig. 6c, d), consistent with the diminished mitochondrial oxygen consumption and energy expenditure in mice observed in the absence of the kinase (Fig. 5), and providing a potential explanation for the delayed insulin resistance of fat-fed Prkce ${ }^{-/-}$mice.

\section{Discussion}

We have demonstrated that $\mathrm{PKC} \varepsilon$ plays a temporally dependent role in the development of insulin resistance. Prkce ${ }^{-/-}$mice fed a high-fat diet for 1-16 weeks exhibited protection against glucose intolerance when compared with fat-fed WT animals, which was associated initially with lower insulin levels, consistent with the preservation of insulin sensitivity. At the same time, fatty acid esterification was promoted in the liver, at the expense of $\beta$-oxidation, resulting in accumulation of triacylglycerol. While glucose tolerance remained enhanced at 16 weeks, insulin levels were elevated above those observed in WT mice, most likely compensating for the development of insulin resistance in Prkce ${ }^{-/-}$mice, in agreement with the augmentation of insulin secretion as previously observed using isolated pancreatic islets chronically treated with fatty acid [9]. By 16 weeks in the present study, hepatic lipid accumulation was equivalently increased in the presence or absence of $\mathrm{PKC} \varepsilon$. The delineation of this novel progression helps to reconcile the findings reported for the ablation of $\mathrm{PKC} \varepsilon$ in acute [8] and longer term [9] models of lipid excess, and provides mechanistic insights into the role of the kinase in glucose homeostasis, as discussed below.

Although $\mathrm{PKC} \varepsilon$ activation has been implicated in the generation of skeletal muscle insulin resistance $[2,3,23]$, the lack of glucose intolerance we observed in Prkce ${ }^{-/-}$mice after 1 week of fat feeding is unlikely to be due to effects on glucose disposal in this tissue, because there was no difference in glucose uptake into quadriceps muscle from $\mathrm{WT}$ and Prkce ${ }^{-/-}$mice in vivo. The liver is therefore the most likely site of $\mathrm{PKC} \varepsilon$ action, as previously suggested [6-9, 24], and we therefore focused our investigation on this tissue.

The association of enhanced insulin action with increased lipid levels in liver argues against a role here for the accumulation of inhibitory lipid mediators in the generation of insulin resistance, which has been suggested to occur upon mitochondrial dysfunction and a reduction in fatty acid catabolism [25]. Several studies now indicate that increased levels of triacylglycerol and diacylglycerol are not always associated with insulin resistance [26-28]. On the one hand, this may reflect the presence of distinct pools of lipids with differing ability to affect insulin action [27]. 
On the other hand, the shunting of fatty acid towards esterification may provide a protective mechanism against the detrimental effects of lipid overload and elevated $\beta$ oxidation [29-32]. This may prevent the build-up of ROS or products of incomplete $\beta$-oxidation, such as specific acylcarnitine esters, which have been linked to insulin resistance $[33,34]$. A reduction in $\beta$-oxidation in association with improved insulin sensitivity has been described predominantly in muscle $[31,34]$ and is in direct contrast to other findings indicating a positive role for $\beta$-oxidation [35-37]. However, we now suggest the reduction we have observed may be beneficial in the liver under conditions of short-term lipid oversupply, especially as we observed a decrease in ROS generation in lipid-treated Prkce hepatocytes. The repartitioning of fatty acids towards esterification in livers of Prkce ${ }^{-/-}$mice fat-fed for 1 week may therefore be sufficient to explain the protection of glucose tolerance in these animals.

We did not observe $\mathrm{PKC} \varepsilon$-dependent alterations in insulin signal transduction at this time, in contrast to the results of a study employing short-term Prkce knockdown in vivo [8]. It is possible that any subtle diet- and genotypedependent effects present after 1 week cannot be detected upon the injection of a bolus of maximal insulin, as we used here. Our results are, however, in agreement with previous work showing that defects in proximal insulin signalling are only observed after several weeks of high-fat feeding and may not be the initial cause of insulin resistance, which may lie downstream of Akt [38]. We have been able to demonstrate diet-induced inhibition of insulin signalling in the liver after 16 weeks of fat feeding [9], but this was not reversed by Prkce deletion, suggesting that $\mathrm{PKC} \varepsilon$-independent mechanisms are more important in the maintenance of insulin resistance in the longer term.

The PKC family has previously been linked to fatty acid metabolism. Other PKC isoforms, such as PKC $\delta$ [39], $\operatorname{PKC} \zeta$ [40] and PKC $\lambda$ [41], have been implicated in lipid synthesis mediated by the transcription factor SREBP1c. Interestingly, $\mathrm{PKC} \delta$ deletion improves insulin action in the longer term, in association with diminished hepatic lipogenesis and triacylglycerol content [39], in direct contrast to the effects we now describe for Prkce deletion, further supporting a progression of mechanisms contributing to insulin resistance. In addition, mRNA expression of Srebf1 and other key regulators of lipid and mitochondrial metabolism, such as $\mathrm{Nr} 1 \mathrm{~h} 3$, and Pparga were unaltered in livers from $\mathrm{Prkce}^{-/-}$mice, suggesting a post-transcriptional role of $\mathrm{PKC} \varepsilon$. However, $\mathrm{PKC} \varepsilon$ also appears to act independently of the regulation of lipid partitioning by AMP-dependent protein kinase (AMPK), which modulates acetyl-CoA carboxylase (ACC) activity and malonyl-CoA production to promote fatty acid uptake into mitochondria via carnitine palmitoyltransferase 1 (CPT1) [42]. No differences in the total levels or phosphorylation state of AMPK, ACC or CPT1 were observed in the liver of Prkce mice under any conditions (data not shown).

The increased energy expenditure we have observed in fat-fed WT mice measured by indirect calorimetry has been reported in other studies [43, 44]. This increase was not observed in $\mathrm{Prkce}^{-/-}$mice after 1 week of fat feeding, which is in agreement with the increased hepatic lipid accumulation in these animals at this time. Although total food intake and body weight were not significantly affected, this may be due to the small magnitude of any changes occurring in this period. No differences in weight were observed after 16 weeks of fat feeding, but by this time hepatic lipid content was equally elevated in WT and Prkce $^{-/-}$mice. Isolated mitochondria from livers of shortterm fat-fed $\mathrm{Prkce}^{-/-}$mice also exhibited a lower respiration rate compared with those from fat-fed WT mice. Because this was measured independently of fatty acid availability, this may indicate a direct site of $\mathrm{PKC} \varepsilon$ action, although we did not detect changes in protein content or activity of individual mitochondrial components. Further studies are required to determine the substrate(s) phosphorylated by $\mathrm{PKC} \varepsilon$ to induce its effects on lipid metabolism and energy expenditure. However, taken together, our data suggest that $\mathrm{PKC} \varepsilon$ is involved in the early adaptation to increased dietary fat supply, promoting fat oxidation to preserve energy balance.

The effects of Prkce deletion on hepatic lipid metabolism presented here are remarkably similar to those we have recently described for Prkce ablation in pancreatic islets [45]. Islets from $P_{r k c e}{ }^{-/-}$mice exhibited diminished fatty acid oxidation and enhanced esterification, which promoted the amplification pathway of glucose-stimulated insulin secretion [45]. This mechanism accounts in part for the improved insulin response during the glucose tolerance test observed in Prkce ${ }^{-/}$mice fat-fed for 16 weeks [9]. It is therefore tempting to speculate that the mechanisms of action of $\mathrm{PKC} \varepsilon$ regulating lipid metabolism in liver and in beta cells are closely related and may involve identical protein targets. In each case, the outcome of Prkce ablation is associated with improved glucose homeostasis, through either protection of insulin action or compensation for insulin resistance by enhanced insulin availability. Whichever mechanism is predominant at any given stage during disease progression, $\mathrm{PKC} \varepsilon$ would therefore represent a key target for the treatment of insulin resistance. Importantly, inhibition of $\mathrm{PKC \varepsilon}$ is unlikely to exacerbate hepatic lipid accumulation in the longer term as this effect appears to be a transient function of fat oversupply. We speculate that kinase normally promotes hepatic oxidation of excess lipid in the short term, which transiently but significantly contributes to insulin resistance. In the longer term, with increased fat accumulation, this hepatic effect of the kinase 
may be overwhelmed, and the major causes of insulin resistance also become $\mathrm{PKC} \varepsilon$ independent.

In conclusion, we have demonstrated that the effect of Prkce deletion is exerted at different sites over the course of feeding a long-term high-fat diet, which can be recapitulated through treatment with a PKCE-inhibitory peptide. In both liver and beta cells the underlying mechanism may involve changes in lipid partitioning. It appears that absence of the kinase protects against lipid-induced insulin resistance in an acute fashion, most likely by reducing acute detrimental effects of increased hepatic $\beta$-oxidation, such as the release of ROS. In the longer term, Prkce ablation promotes glucose-stimulated insulin secretion by beta cells, promoting an enhanced response to blood glucose elevations in the face of insulin resistance. We have therefore reconciled recent studies reporting distinct effects of Prkce ablation, and reinforce the importance of this enzyme as a site of therapeutic intervention upon impaired glucose homeostasis.

Acknowledgements This research was supported by grants from the National Health and Medical Research Council of Australia (to C. Schmitz-Peiffer and T.J. Biden) and the Diabetes Australia Research Trust (to C. Schmitz-Peiffer). K. Raddatz was supported by a Research Fellowship from the Deutsche Forschungsgemeinschaft. N. Turner is supported by a Career Development Award from the NHMRC. The authors wish to acknowledge the expert technical assistance of the Garvan Institute Biological Testing Facility. We also thank G. Cooney and L. Zhang (Diabetes and Obesity and Neuroscience Programs, Garvan Institute) for critical evaluation of the manuscript.

Duality of interest C. Schmitz-Peiffer and T.J. Biden have received support from Kai Pharmaceuticals (San Francisco, CA, USA) for evaluation of inhibitors of $\mathrm{PKC} \varepsilon$ in the context of type 2 diabetes. The other authors declare that there is no duality of interest associated with this manuscript.

\section{References}

1. Schmitz-Peiffer C, Biden TJ (2008) Protein kinase C function in muscle, liver, and beta-cells and its therapeutic implications for type 2 diabetes. Diabetes 57:1774-1783

2. Schmitz-Peiffer C, Browne CL, Oakes ND et al (1997) Alterations in the expression and cellular localization of protein kinase $\mathrm{C}$ isozymes epsilon and theta are associated with insulin resistance in skeletal muscle of the high-fat-fed rat. Diabetes 46:169-178

3. Laybutt DR, Schmitz-Peiffer C, Saha AK, Ruderman NB, Biden TJ, Kraegen EW (1999) Muscle lipid accumulation and protein kinase $\mathrm{C}$ activation in the insulin-resistant chronically glucoseinfused rat. Am J Physiol 277:E1070-E1076

4. Qu X, Seale JP, Donnelly R (1999) Tissue and isoform-selective activation of protein kinase $\mathrm{C}$ in insulin-resistant obese Zucker rats-effects of feeding. J Endocrinol 162:207-214

5. Ikeda Y, Olsen GS, Ziv E et al (2001) Cellular mechanism of nutritionally induced insulin resistance in Psammomys obesus: overexpression of protein kinase $\mathrm{C}$ epsilon in skeletal muscle precedes the onset of hyperinsulinemia and hyperglycemia. Diabetes 50:584-592
6. Samuel VT, Liu ZX, Qu X et al (2004) Mechanism of hepatic insulin resistance in non-alcoholic fatty liver disease. J Biol Chem 279:32345-32353

7. Considine RV, Nyce MR, Allen LE et al (1995) Protein kinase C is increased in the liver of humans and rats with non-insulindependent diabetes mellitus: an alteration not due to hyperglycemia. J Clin Invest 95:2938-2944

8. Samuel VT, Liu ZX, Wang A et al (2007) Inhibition of protein kinase $\mathrm{C}$ epsilon prevents hepatic insulin resistance in nonalcoholic fatty liver disease. J Clin Invest 117:739-745

9. Schmitz-Peiffer C, Laybutt DR, Burchfield JG et al (2007) Inhibition of PKCepsilon improves glucose-stimulated insulin secretion and reduces insulin clearance. Cell Metab 6:320-328

10. Cai D, Yuan M, Frantz DF et al (2005) Local and systemic insulin resistance resulting from hepatic activation of IKK-beta and NFkappaB. Nat Med 11:183-190

11. Cantley J, Choudhury AI, Asare-Anane H et al (2007) Pancreatic deletion of insulin receptor substrate 2 reduces beta and alpha cell mass and impairs glucose homeostasis in mice. Diabetologia 50:1248-1256

12. Preece A (1972) A manual for histologic technicians-paraffin tissue processing method. Little Brown, Boston, pp 57-73

13. Folch J, Lees M, Sloane Stanley GH (1957) A simple method for the isolation and purification of total lipids from animal tissues. $\mathrm{J}$ Biol Chem 226:497-509

14. Nakamura K, Handa S (1984) Coomassie brilliant blue staining of lipids on thin-layer plates. Anal Biochem 142:406-410

15. Cazzolli R, Mitchell TW, Burchfield JG et al (2007) Dilinoleoylphosphatidic acid mediates reduced IRS-1 tyrosine phosphorylation in rat skeletal muscle cells and mouse muscle. Diabetologia $50: 1732-1742$

16. Turner N, Bruce CR, Beale SM et al (2007) Excess lipid availability increases mitochondrial fatty acid oxidative capacity in muscle: evidence against a role for reduced fatty acid oxidation in lipid-induced insulin resistance in rodents. Diabetes 56:20852092

17. Bruce CR, Thrush AB, Mertz VA et al (2006) Endurance training in obese humans improves glucose tolerance and mitochondrial fatty acid oxidation and alters muscle lipid content. Am J Physiol 291:E99-E107

18. Berry MN, Friend DS (1969) High-yield preparation of isolated rat liver parenchymal cells: a biochemical and fine structural study. J Cell Biol 43:506-520

19. Achouri Y, Hegarty BD, Allanic D et al (2005) Long chain fatty acyl-CoA synthetase 5 expression is induced by insulin and glucose: involvement of sterol regulatory element-binding protein1c. Biochimie 87:1149-1155

20. Busch AK, Gurisik E, Cordery DV et al (2005) Increased fatty acid desaturation and enhanced expression of stearoyl coenzyme A desaturase protects pancreatic beta-cells from lipoapoptosis. Diabetes 54:2917-2924

21. Eriksson JW (2007) Metabolic stress in insulin's target cells leads to ROS accumulation - a hypothetical common pathway causing insulin resistance. FEBS Lett 581:3734-3742

22. Murphy MP (2009) How mitochondria produce reactive oxygen species. Biochem J 417:1-13

23. Schmitz-Peiffer C, Oakes ND, Browne CL, Kraegen EW, Biden TJ (1997) Reversal of chronic alterations of skeletal muscle protein kinase C from fat-fed rats by BRL-49653. Am J Physiol 273:E915-E921

24. Matsuzaka T, Shimano H, Yahagi N et al (2007) Crucial role of a long-chain fatty acid elongase, Elovl6, in obesity-induced insulin resistance. Nat Med 13:1193-1202

25. Morino K, Petersen KF, Shulman GI (2006) Molecular mechanisms of insulin resistance in humans and their potential links with mitochondrial dysfunction. Diabetes 55(Suppl 2):S9-S15 
26. Monetti M, Levin MC, Watt MJ et al (2007) Dissociation of hepatic steatosis and insulin resistance in mice overexpressing DGAT in the liver. Cell Metab 6:69-78

27. Minehira K, Young SG, Villanueva CJ et al (2008) Blocking VLDL secretion causes hepatic steatosis but does not affect peripheral lipid stores or insulin sensitivity in mice. J Lipid Res 49:2038-2044

28. Nagle CA, Klett EL, Coleman RA (2009) Hepatic triacylglycerol accumulation and insulin resistance. J Lipid Res 50(Suppl):S74S79

29. Guerre-Millo M, Rouault C, Poulain P et al (2001) PPAR-alphanull mice are protected from high-fat diet-induced insulin resistance. Diabetes 50:2809-2814

30. Tordjman K, Bernal-Mizrachi C, Zemany L et al (2001) PPARalpha deficiency reduces insulin resistance and atherosclerosis in apoE-null mice. J Clin Invest 107:1025-1034

31. Finck BN, Bernal-Mizrachi C, Han DH et al (2005) A potential link between muscle peroxisome proliferator-activated receptoralpha signaling and obesity-related diabetes. Cell Metab 1:133-144

32. Muoio DM (2010) Intramuscular triacylglycerol and insulin resistance: guilty as charged or wrongly accused? Biochim Biophys Acta 1801(3):281-288

33. Newsholme P, Haber EP, Hirabara SM et al (2007) Diabetes associated cell stress and dysfunction: role of mitochondrial and non-mitochondrial ROS production and activity. J Physiol 583:9-24

34. Koves TR, Ussher JR, Noland RC et al (2008) Mitochondrial overload and incomplete fatty acid oxidation contribute to skeletal muscle insulin resistance. Cell Metab 7:45-56

35. Perdomo G, Commerford SR, Richard AMT et al (2004) Increased beta-oxidation in muscle cells enhances insulinstimulated glucose metabolism and protects against fatty acidinduced insulin resistance despite intramyocellular lipid accumulation. J Biol Chem 279:27177-27186

36. Choi CS, Savage DB, Abu-Elheiga L et al (2007) Continuous fat oxidation in acetyl CoA carboxylase 2 knockout mice increases total energy expenditure, reduces fat mass, and improves insulin sensitivity. Proc Natl Acad Sci USA 104(42):16480-16485

37. Bruce CR, Hoy AJ, Turner N et al (2009) Overexpression of carnitine palmitoyltransferase-1 in skeletal muscle is sufficient to enhance fatty acid oxidation and improve high-fat diet-induced insulin resistance. Diabetes 58:550-558

38. Hoehn KL, Hohnen-Behrens C, Cederberg A et al (2008) IRS1independent defects define major nodes of insulin resistance. Cell Metab 7:421-433

39. Frangioudakis G, Burchfield JG, Narasimhan S et al (2009) Diverse roles for protein kinase $\mathrm{C}$ delta and protein kinase $\mathrm{C}$ epsilon in the generation of high-fat-diet-induced glucose intolerance in mice: regulation of lipogenesis by protein kinase $\mathrm{C}$ delta. Diabetologia 52:2616-2620

40. Liu LZ, He AB, Liu XJ, Li Y, Chang YS, Fang FD (2006) Protein kinase $C$ zeta and glucose uptake. Biochemistry (Mosc) 71:701706

41. Matsumoto M, Ogawa W, Akimoto K et al (2003) PKC lambda in liver mediates insulin-induced SREBP-1c expression and determines both hepatic lipid content and overall insulin sensitivity. J Clin Invest 112:935-944

42. Hardie DG, Pan DA (2002) Regulation of fatty acid synthesis and oxidation by the AMP-activated protein kinase. Biochem Soc Trans 30:1064-1070

43. Seth A, Steel JH, Nichol D et al (2007) The transcriptional corepressor RIP140 regulates oxidative metabolism in skeletal muscle. Cell Metab 6:236-245

44. Chiu HK, Qian K, Ogimoto K et al (2010) Mice lacking hepatic lipase are lean and protected against diet-induced obesity and hepatic steatosis. Endocrinology 151:993-1001

45. Cantley J, Burchfield JG, Pearson GL, Schmitz-Peiffer C, Leitges M, Biden TJ (2009) Deletion of PKCE selectively enhances the amplifying pathways of glucose-stimulated insulin secretion via increased lipolysis in mouse $\beta$-cells. Diabetes 58(8):1826-1834 